\title{
Infections caused by Acinetobacter species and their susceptibility to 14 antibiotics in Lagos University Teaching Hospital, Lagos.
}

\author{
*K C. Iregbu, F. T. Ogunsola and T. O. Odugbemi \\ * Department of Medical Microbiology \& Parasitology, National Hospital \\ P.M.B.425, Garki,Abuja E-mail: kciregbu@hotmail.com \\ Department Of Medical Microbiology \& Parasitology, Lagos University \\ Teaching Hospital/College OfMedicine, University OfLagos, Lagos, Nigeria
}

\begin{abstract}
Summary
Acinetobacter spp are well recognised as causes of nosocomial infections particularly in patients with immature or defective body defence system. Information concerning these organisms are lacking in this environment. For this reason the pattern of infection and the antimicrobial susceptibility profiles of these organisms isolated over a one-year period were studied.
\end{abstract}

A total of $58(3 \%)$ of the 2001 isolates from all clinical specimens received in the laboratory during the year were Acinetobacter spp. . The 58 Acinetobacter spp constituted 5.5\% of all the 1051 NLF-GNB isolated, and caused $4.6 \%$ of all the 1261 nosocomial infections. Thirty-seven (63\%) and $17(30 \%)$ of the Acinetobacter isolates were from wound infections and UTI respectively. All the infections were nosocomially acquired and were associated with compromised host immunity, defective body defence, surgery or urinary catheterization; with Acinetobacter baumannii being the predominant species. There was an apparent male predominance over females by a ratio of 1. 9:1 in the infections, particularly from 45 years and above. One hundred percent and $96.6 \%$ of the isolates were susceptible to cefoperazone-sulbactam and travofloxacin respectively. Forty-five (77.6\%) were susceptible to cefotaxime, $49(84.5 \%)$ to ampicillin-sulbactam, $34(58.6 \%)$ to ceftazidime, $38(65.6 \%)$ to ticarcillin-clavulanic acid and $41(\mathbf{7 0 . 7 \%})$ to ciprofloxacin. Generally the Acinetobacter spp showed multiple resistance to the range of antibiotics tested. All the isolates produced betalactamase.

Key words: Acinetobacter, Epidemiology, Antimicrobial susceptibility

\section{Résumé}

Les Acinetobacters spp sont bien reconnus commes les causes des infections nosocomiaux en particulier chez les patients avec le système de la defense du corps defectif ou immaturé. On manque des informations adéquates concernant ces organismes dans cet environnement. A cause de cette raison, le modèle de l'infection et les profiles de la susceptibilité antimicrobien de ces organismes isolès au cours de la période d'une année ont été étudiés.

Le nombre total de 58 soit $3 \%$ de 2001 isolés de tous les spécimens cliniques reçu dans le laboratoire durant cette année étaient Acinetobacters spp. Tous les cas de 58 Acinetobacters spp avaient constitué $5,5 \%$ de tous les 1051 NLF-GNB isolés et ont causé $4,6 \%$ de tous 1261 cas des infections nosocomiales. Trente sept soit $63 \%$ et 17 soit $30 \%$ de cas des isolés Acinetobacters résultent des infections des blessures et de UTI respectivement. Toutes les infections sont acquises à travers la nosocomiale et elles avaient des rapports avec la faiblesse de l'immaturité de l'hóte, la défense du corps défectueux, la chirurgie ou la catéchisation urinaire, avec Acinetobacter baumannil qui était l'espèce le plus prédominant. On avait noté la predominance de male par rapport aux femmes dans la proportion 1: 9: 1 dans l'infection à partir de l'âge de 45 et au dessus en particulier. Cent pour cent et $96.6 \%$ des isolés étaient susceptibles au cefoperazone-sulbacta, et travofloxacine respectivement. Quarante cinq soit $84.5 \%$ au ampicilline-sulbacta, 34 soit $58.6 \%$ au ceftazidime, 38 soit $65.6 \%$ a l'acide ticareilline* Correspondence clavulanie et 41 soit 70,7\% au ciproflozacine. Dans l'ensemble, l' Acinetobacter spp. a indiqué une résistance multiple au champs des épreuves antibiotiques. Tous les isolés avaient produit betalactamase.

\section{Introduction}

The genus Acinetobacter was originally placed in the family of Neisseriacea but has recently been moved to the family of Moraxellacea $e^{\prime}$. Acinetobacter spp are widespread in nature and in the hospital environment, and are the second most commonly isolated non-fermenters in human specimens. ${ }^{2}$

The genus consists of strictly aerobic, gram-negative coccobacillary rods that are oxidase negative, non-motile, nitrate negative and nonfermentative. ${ }^{2}$ The colonies are smooth, opaque, and slightly smaller than those of Enterobacteriaceae. ${ }^{2}$ Many strains grow on MacConkey agar as either colourless or slightly pinkish colonies. ${ }^{2}$ Some strains are fastidious, showing punctate colonies on blood agar, and fail to grow in nutrient broth. ${ }^{2}$ Acinetobacter spp are most commonly found in the soil, water and as part of the normal flora on human skin and in the gastrointestinal and upper respiratory tracts. ${ }^{2,3}$ The genus consists of about 21 different DNA groups or genomospecies ${ }^{4,5,6}$ some of which are widely distributed in most hospital environments, and have been implicated in a variety of nosocomial infections including bacteraemia, urinary tract infections, pneumonia and wound infections. ${ }^{2,7}$ These infections are usually difficult to treat because Acinetobacter spp are often multiple resistant to the major groups of antimicrobials and therefore, usually require combination therapy.?

The therapeutic problems are compounded by the fact that these bacteria have the capacity to survive for a long time in the hospital environment and are easily transmitted between patients either through human reservoirs or inanimate materials. ${ }^{2}$ This situation has led to an increased concern regarding nosocomial infections due to this organism. Risk factors associated with Acinetobacter infections include antibiotic treatments, surgery, instrumentation, and stay in the intensive care unit. ${ }^{7,8}$ A previous study has shown that the digestive tracts of patients in the intensive care unit are important epidemiologic reservoirs for multidrug-resistant Acinetobacter baumannii, the most commonly isolated species. ${ }^{9}$ In spite of the increasing significant and prevalence of multiply resistant Acinetobacter spp, many Clinicians and Microbiologists still have not appreciated their importance, partly because of the confused taxonomic status, which until recently was associated with these organisms ${ }^{10}$ and party because the laboratories are not identifying them. This may have accounted for the absence of any known local work on Acinetobacter spp. This study was designed to highlight the status of Acinetobacter spp in hospital infections; including their epidemiology and antibiotic susceptibility profile.

\section{Materials \& Methods}

All non-lactose fermenting (NLF) Gram-negative bacilli (GNB) adjudged as clinically significant from proven hospital acquired infections were studied, from where 58 Acinetobacter spp were identified. Thirty seven (63\%) of the 58 Acinetobacter isolates were from wound infections, $17(30 \%)$ from urinary tract infections (UTI) and $4(7 \%)$ from bacteraemia. 
The isolates were sub-cultured onto nutrient and MacConkey agar, for purification, and incubated in air at $35-37^{\circ} \mathrm{C}$ for $18-24$ hours. Pure colonies were used for subsequent tests. Those isolates that were non-motile, oxidase-negative morphologically Gramnegative coccobacillary and showing alkaline butt and slope on a TSI medium (DIFCO Laboratories, Detroit, Michigan, USA) were considered to be non-fermentative, and tentatively identified as Acinetobacter spp. ${ }^{11}$ They were further identified by the API 2 ONE (bioMerieux SA, Marcy-l'Etiole, France).

The 58 Acinetobacter isolates were tested against Ceftriaxone, Cefuroxime, Ceftazidime Cefotaxime, Cefoperazone-Sulbactam, Ampicillin-sulbactam, Amoxycillin-Clavulanate, TicarcillinClavulanate, Gentamicin, Streptomycin, TrimethoprimSulfamethoxazole, Ciprofloxacin, Travofloxacin and Nalidixic Acid for susceptibility by the gradient diffusion method using the Elipsometer (E-test) strips (AB-Biodisk Solna Sweden). ${ }^{12}$ The betalactamase detection test was done by the starch paper technique. ${ }^{13}$ Escherichia coli ATCC 25922 was used as control ${ }^{14}$

\section{Results}

Table 1 shows that $38(65.5 \%)$ of the 58 Acinetobacter infections occurred in males while $20(34.5 \%)$ occurred in females. Males aged 45 years and above accounted for $28(48.3 \%)$ of all the infections while females in the same age group accounted for only $6(10.3 \%)$. Only $4(6.8 \%)$ occurred in children 14 years and below.

\begin{tabular}{cccc}
\multicolumn{4}{c}{ Table 1 Distribution of Acinetobacter isolates by age and sex } \\
\hline Age & Male (\%) & Female (\%) & Total (\%) \\
$0-1$ month & $1(1.72)$ & - & $1(1.72)$ \\
$>1$ month -1 yr & - & $1(1.72)$ & $1(1.72)$ \\
$>1$ yr. -4 yrs & - & $1(1.72)$ & $1(1.72)$ \\
$5-14$ yrs & $1(1.72)$ & - & $1(1.72)$ \\
$15-44 \mathrm{yrs}$ & $8(13.79)$ & $12(20.70)$ & $20(34.49)$ \\
$45-59$ yrs & $12(20.70)$ & $5(8.63)$ & $17(29.33)$ \\
60yrs \& above & $16(27.58)$ & $1(1.72)$ & $17(29.30)$ \\
Total & $\mathbf{3 8 ( 6 5 . 5 1 )}$ & $\mathbf{2 0 ( 3 4 . 4 9 )}$ & $\mathbf{5 8 ( 1 0 0 )}$ \\
\hline
\end{tabular}

Table 2 Distribution of Acinetobacter spp in various clinical specimens

\begin{tabular}{lcc}
\hline Specimens & No (\%) & Total (\%) \\
Wound swab: & & $37(63)$ \\
$\quad$ Post - surgical & $24(41)$ & \\
I. V. - line related & $3(5)$ & \\
Road Traffic Accident & $4(7)$ & \\
$\quad$ Ulcer & $3(5)$ & \\
Gun-shot & $1(2)$ & \\
$\quad$ Burns & $2(3)$ & $17(30)$ \\
Urine: & & \\
$\quad$ Mid-stream urine & $1(2)$ & $4(7)$ \\
$\quad$ Catheter-specimen urine & $16(28)$ & $58(100)$ \\
Bacteraemia & $4(7)$ & \\
Total & & \\
\hline
\end{tabular}

Table 3 shows the species distribution. Acinetobacter baumannii constituted $50(86.2 \%)$ of the 58 species isolated.

Table 3 Prevalence of Acinetobacter spp* isolated from clinical specimens

\begin{tabular}{lc}
\hline Species & No. (\%) \\
& \\
Acinetobacter baumannii & $50(86.2)$ \\
Acinetobacter Wwoffi & $3(5.2)$ \\
Acinetobacter johnsonii/junii & $3(5.2)$ \\
Acinetobacter haemolyticus & $2(3.4)$ \\
Total & $58(100)$ \\
\hline
\end{tabular}

"Species identified by API $20 N E$

Out of a total of 1051 NLF-GNB analysed during the period, 58
(5.5\%) were Acinetobacter spp. Of these $37(63 \%$, were isolated from wound swabs, i.e. post-surgical wound infecticns. Seventeen $(30 \%)$ were from cases of UTI, mainly catheterised patients, while $4(7 \%)$ were from bacteraemias (Table 2 ).

It is shown in Table 4 that all the Acinetobacter isolates were susceptible to cefoperazone-sulbactam, $96.6 \%$ to travofloxacin, $84.5 \%$ to ampicillin-sulbactam, 77.65 to cefotaxime and $70.7 \%$ to ciprofloxacin. Only 55.25 were susceptible to gent:amicin and nalidixic acid and $10.4 \%$ to trimethoprim-sulphamet ioxazole. All the isolates produced beta-lactamase enzymes.

Table 4 Antimicrobial susceptibility pattern of Acinetc bacter spp

\begin{tabular}{lcccc}
\hline Antimicrobial Agent & $\begin{array}{c}\text { Number } \\
\text { Tested }\end{array}$ & $\begin{array}{c}\text { Number } \\
\text { susceptible } \\
\text { (\%) }\end{array}$ & $\begin{array}{c}\text { Number } \\
\text { moderatily } \\
\text { susceptille }\end{array}$ & $\begin{array}{c}\text { Number } \\
\text { Resistant } \\
(\%)\end{array}$ \\
Ceftriaxone & & & $(\%)$ & \\
Cefuroxime & 58 & $15(25.9)$ & $5(8.6)$ & $38(65.5)$ \\
Ceftazidime & 58 & $5(8.6)$ & $3(5.2)$ & $50(86.2)$ \\
Cefotaxime & 58 & $34(58.6)$ & $12(20.7)$ & $12(20.7)$ \\
Cefoperazone-Sulbactam & 58 & $45(77.6)$ & $13(22.4)$ & $-(0)$ \\
Ampicillin-Sulbactam & 58 & $58(100)$ & $-(0)$ & $-(0)$ \\
Amoxycillin-Clavulanate & 58 & $12(20.7)$ & $14(24.1)$ & $32(55.2)$ \\
Ticarcillin-Clavulanate & 58 & $38(65.5)$ & $6(10.4)$ & $14(24.1)$ \\
Gentamicin & 58 & $32(55.2)$ & $-(0)$ & $26(44.8)$ \\
Streptomycin & 58 & $28(48.3)$ & $-(0)$ & $30(51.7)$ \\
Trimethoprim- & & & & \\
Sulfamethoxazole & 58 & $6(10.4)$ & $-(0)$ & $52(89.6)$ \\
Ciprofloxacin & 58 & $41(70.7)$ & $-(0)$ & $17(29.3)$ \\
Trovofloxacin & 58 & $56(96.6)$ & $2(3.4)$ & $-(0)$ \\
Nalidixic Acid & 58 & $32(55.2)$ & $6(10.3)$ & $20(34.5)$ \\
\hline
\end{tabular}

Discussion

This study was carried out to determine the epir lemiology and antibiotic susceptibility profile of $A$ cinetobacter spp. It is obvious from the result of the study that Acinetobacter spp cause significant nosocomial infections, being responsible for $4.6 \%$ of all the nosocomial infections seen during the study period as against the $3 \%$ recorded in the National Nosocomial Infection S ltudy report to the CDC in $1990 .{ }^{15}$ This is particularly signif cant because Acinetobacter spp are known to be the most persiste it Gram-negative bacilli on the hands of hospital staff, ${ }^{16}$ and so can easily be transferred from one patient to another. This may probably explain why $37(63 \%)$ of the infections were wound infections, and a total of $50(86.2 \%)$ occurred in the surgery unit w] iere hand contamination of wound and catheters are fairly commo.$^{16}$ Elsewhere Acinetobacter spp are known to cause significant nosocomial respiratory tract infection in patients in the intensive c re unit. ${ }^{17}$ The absence of such findings here may be attributed to the non-functioning of the unit in the hospital during the study period, and so no specimen was received from the unit. The four cases of bacteraemia constituted $4.9 \%$ of all cases of bactera mia seen during the study. This is slightly higher than record $d$ in previous studies (2-4\%). ${ }^{18,19}$ All the bacteraemias occurred in children, two of whom were infants (one neonate), and were all rilated to intravenous infusions. Generally the infections were a sociated with compromised body immunity such as surgery, cathe isation, burns and intravenous lines. Similar findings have been n ade from previous studies. ${ }^{20-24}$ Acinetobacter baumannii, like in other studies, 2,7 predominated in all the infections, constituting $5(.86 .2 \%)$ of all the species isolated. Males aged 45 years and abov a appear to be more susceptible than females in the same age rang:. This can be attributed to higher prevalence of indwelling cathet $r$ in this group as a result of prostatic enlargement and its associate 1 surgery.

Acinetobacter spp are generally known to ex hibit multiple resistance to various antibiotics. ${ }^{25-28}$ In the 1970 s, Acinetobacter infections were treated with Ampicillin, second-gen ration cephalosporins, minocycline, colistin, Carbenicillin, and Gentamicin. ${ }^{24}$ 
Most strains are now resistant to Ampicillin, Carbenicillin, Cefotaxime, and Chloramphenicol, with some centres reporting up to $84 \%$ of strains resistant to Gentamicin. ${ }^{29}$ In this study $77.6 \%$ of strains were susceptible to Cefotaxime whereas only $25.9 \%, 8.6 \%$ and $58.6 \%$ of Ceftriaxone, Cefurozime and Ceftazidime respectively were susceptible. This may be the response to selective pressure since these later three drugs are the most commonly used cephalosporins in this environment. A resistance level of $86.2 \%$ against Cefuroxime is similar to what has been found in Europe ${ }^{30}$ while $15-62 \%$ of Acinetobacter spp in Hong Kong, Malaysia, and Singapore, and $68-100 \%$ of strains in China and Taiwan are resistant to third-generation cephalosporins. ${ }^{31}$ It is noteworthy that drugs containing the beta-lactamase inhibitor Sulbactam showed higher antibacterial activity against Acinetobacter spp than those containing clavulanic acid. This may likely be due to the unusual inhibitory activity of Sulbactam against Acinetobacter species. ${ }^{32}$ Susceptibilies of the strains to Cefoperazone-sulbactam and Ampicillin-sulbactam were $100 \%$ and $84.5 \%$ respectively while only $20.7 \%$ and $65.5 \%$ were susceptible to Amoxycillin-clavulanate and Ticarcillin-clavulanate respectively. Cefoperazone-sulbactam, Ampicillin-sulbactam and Imipenem have been found to be the most active against Acinetobacter spp in Argentina and Hungary ${ }^{30,33}$ The organisms showed high resistance to both gentamicin and streptomycin. Similar findings have been made elsewhere. ${ }^{30,31,33,34}$ Gentamicin is the most commonly used aminoglycoside in LUTH.

Ninety-six to $100 \%$ of the strains were susceptible to travofloxacin while $70.7 \%$ were susceptible to ciprofloxacin. In Europe and Latin America $50-70 \%$ of the strains have been found to be resistant to ciprofloxacin ${ }^{30,33}$. The indiscriminate use of the third generation cephalosporins in this hospital and the general abuse of drugs by the people ${ }^{35}$ may have accounted for the increasing resistance level found against the tested drugs and probably others. The newer members of the third generation cephalosporins and the fluoroquinolones appeared more effective than their older members. This observation has also been previously noted.' All the isolates were found to be beta-lactamase producers, a situation which may also have contributed to the multiple resistant nature of the organisms.

\section{References}

1. Fass R J, Barnishan J. In vitro susceptibility of nonfermentative gramnegative bacilli other than Pseudomonas aeruginosa to 32 antimicrobial agents. Rev. Infect Dis 1980; 2: 841-853.

2. Schreckenberger P C, VONGraevenitz A. Acinetobacter, Achromobacter, Alcaligenes, Moraxella, Methylobacterium, and other Non-fermentative Gram-negative Rods. In Murray PR, Baron EJ, Pfaller MA, Tenover, FC, Yolken RH eds. Manual of Clinical Microbiology, 7 th ed. Washington DC 1999; 539-560.

3. Dijkshoorn L, Aucken H, Gerner-Smidt P. Janssen P, Kaufmann ME, Garaizar J, et al. Comparison of outbreak and non-outbreak Acinetobacter baumannii strains by genotypic and phenotypic methods. J Clin Microbiol 1996; 34: 1519-1525.

4. Grimontt P A D, Bouvet P J M. Taxonomy of Acinetobacter, Taxonomy, Clinical importance, molecular biology, physiology, industrial relevance. New York: Plenum 1991; 25 - 36.

5. Ibrahim A P, Gerner-Smidt P, Liesack W. Phylogenic relationship between the twenty-one DNA groups of the genus Acinetobacter as revealed by 16 S ribosomal DNA sequence analysis. Int J Syst Bacteriol 1997; 47: 837-841.

6. Tjemberg W H, Leonard B. Clinical strains of Acinetobacter classified by DNA-DNA hybridization. APMIS 1989: 97: 595-605.

7. Bergogne-Berezin E. Towner K. J. Acinetobacter species as nosocomial pathogen: Microbiological, Clinical and Epidemiological features.
Clin Microbiol Rev 1996; 9: 148-1465.

8. Cisneros J M, Reyes M J, Pachon J, Becerril B, Caballero F J, GarciaGarmendia J L et al. Bacteraemia due to Acinetobacter baumanniii: epidemiology, clinical findings and prognostic features. Clin Infect Dis 1996; 22: 1026-1032.

9. Corbella X, Pujol M, Ayats J, Sendra M, Ardanuy C. Dominguez MA et al. Relevance of digestive tract colonization in the epidemiology of nosocomial infections due to multiresistant Acinetobacter baumannii. Clin Infect Dis 1996; 23: 329-334.

10. Allen D M, Hartman B J. Acinetobacter species. In: Mandell GL, Bennettee JE, Dolin R, Eds. Principles and Practice of Infections Diseases. 4th ed. New York. Churchill Livingstone 1995: vol. 2: 2009-2013.

11. Oduyebo O, Ogunsola F T, Kesah CN, Odugbemi T. Characterisation of non-fermenting gram-negative bacilli at the Lagos University Teaching Hospital - a preliminary report. Nigerian Quarterly Journal of Hospital Medicine 1996; 6: 178-182.

12. Jorgensen J H, Turnidge JD, Washington J A. Antibacterial Susceptibility Tests: Dilution and Disk Diffusion Methods. In Murray PR, Baron EJ, Pfaller MA, Tenover FC, Yolken RH eds. Manual of Clinical Microbiology, 7th ed. Washington DC 1999; 1526 - 1543.

13. Odugbemi T. Hafiz S, McEntegart M G. Penicillinase-producing Neisseria gonorrhoeae: detection by starch paper technique BMJ 1977; 22: 500

14. Jawad A, Hawkey P M, Heritage J, Snelling A M. Description of Leeds Acinetobacter medium, a new selective and differential medium for isolation of clinically important Acinetobacter species, and comparison with Herella agar and Holton agar. J Clin Microbiol 1994; 32: $2353-2358$.

15. Craven D E, Steger K A, Barber T W. Preventing nosocomial pneumonia: state of the art and perspective for the 1990s. Am J Med 1991; 91 (3B): 44S-53S.

16. Adams B G, Marrie T J. Hand carriage of aerobic Gram-negative rods may not be transient. J Hyg, Camb 1982; 89: 33-47

17. Bergogne-Berezin E, Towner J K. Acinetobacter species as nosocomial pathogens: microbiological and epidemiological features. Clin Microbiol Rev 1996; 9: 148-165

18. Weinstein M P, Reller L B, Murphy J R, et al. The clinical significant of positive blood culture: a comprehensive analysis of 500 episodes of bacteraemia and fungaemia in adults. 1. Laboratory and epidemilogic observations. Rev Infect Dis 1983; 5: 35 - 53.

19. Leibovci L, Konisbeger H, Pitlik D S et al. Bacteraemia and fungaemia of unknown origin in adults. Clin Infect Dis 1992; 14: 436 - 443

20. Ng P C, Herrington R A, Beane C A, Ghoneim A T, Dear P R. An outbreak of Acinetobacter septicaemia in a neonatal intensive care unit. J Hosp Infect 1989; 14: 363-368

21. Stone J W, Das B C. Investigation of an outbreak of infection with Acinetobacter calcoaceticus in a special care baby unit. J Hosp Infect $1985 ; 6: 42-48$

22. Bergogne-Berezin E, Joly-Guillou M L. Hospital infection with Acinetobacter species: an increasing problem. J Hosp Infect 1991; 18 (supl A): 250-255

23. Castle M, Tenny J H, Weinstein MP, Eickhoff T C. Outbreak of multiply resistant Acinetobacter in a surgical intensive care nit: epidemiology and control. Heart Lung 1978; 7: 641-644

24. Allen D M, Hartman B J. Acinetobacter species. In Mandell GL, Douglas RG, Bennett JE eds. Principles and Practice of Infectious 
Diseases, 3rd ed. New York. Churchill Livingstone 1990; 1696-1700.

25. Bergogne-Berezin E, Joly-Guillou M L, Vieu J F. Epidemiology of nosocomial infections due to Acinetobacter calcoaceticus. J Hosp Infect 1987; 10: $105-113$.

26. French GL, Casewell M W, Roncoroni A J, Knight S, Phillips I. A hospital outbreak of antibiotic-resistant Acinetobacter anitratus: epidemiology and control. J Hosp Infect 1980; 1: 125 - 131.

27. Buisson Y, Tran Van Nhieu G, Ginot L, Bouvet P, Shill H, Driot L et $a l$. Nosocomial outbreak due to amikacin-resistant tobramycin-sensitive Acinetobacter species: correlation with amikacin usage. J Hosp Infect 1990; 15: 83 - 93.

28. Larson E A decade of nosocomial Acinetobacter. Am J Infect Control 1984; 12: $14-18$

29. Begogne-Berezin E, Joly-Guillou M L. An underestimated Nosocomial pathogen, Acinetobacter calconceticus. J. Antimicrob Chemother $1985 ; 16: 535-538$
30. Issues in Bacterial Resistance: Central and Eastem I iurope-a Pfizer publication on regional seminars on bacterial resistan e (monograph) 1996

31. Issues in Bacterial Resistance: Asia-a Pfizer publicat ion on regional seminars on bacterial resistance (monograph) 1995.

32. Retsema JA, English AR, Girard A, Lynch JE, Anders on M, Brennan L et al. Sulbactam/Ampicillin: in vitro spectrum poten :y, and activity in models of acute infection. Rev Infect Dis 1986; 8(Suppl): S528534.

33. Issues in Bacterial Resistance: Latin America - a Pfi er publication on regional seminars on bacterial resistance (monogra ph) 1996.

34. Seifert H, Baginsky H R, Schulze A, Pulverer G. Ant imicrobial susceptibility of Acinetobacter species. Antimicrob Age ats Chemother 1993: 37: 750-753.

35. Odugbemi $\mathrm{T} O$. The use and abuse of antibiotics. Ni/jerian Medical Journal 1981; $1: 5-8$. 